\title{
Impact of the Coronavirus Pandemic on Family Well-Being: A Rapid and Scoping Review
}

\author{
Takafumi Soejima (1) \\ Division of Family Health Care Nursing, Graduate School of Health Sciences, Kobe University, Hyogo, Japan \\ Email: soejimat@people.kobe-u.ac.jp
}

How to cite this paper: Soejima, T. (2021) Impact of the Coronavirus Pandemic on Family Well-Being: A Rapid and Scoping Review. Open Journal of Nursing, 11, 10641085.

https://doi.org/10.4236/ojn.2021.1112085

Received: November 26, 2021

Accepted: December 26, 2021

Published: December 29, 2021

Copyright $\odot 2021$ by author(s) and Scientific Research Publishing Inc. This work is licensed under the Creative Commons Attribution International License (CC BY 4.0).

http://creativecommons.org/licenses/by/4.0/

\begin{abstract}
The coronavirus disease of 2019 (COVID-19) has had a serious impact not only on the society, economy, and medical system, but also on the families and family members affected by it. This scoping review aimed to describe the effects of the COVID-19 pandemic on family well-being. Original articles in English published between January 2020 and August 2021 that examined the association between COVID-19 and family well-being, were searched on MEDLINE and CINAHL. The literature search was conducted using Mesh or CINAHL Subject Headings on COVID-19 and families. Of the 923 references extracted from MEDLINE and CINAHL, this review included 25 references based on exclusion criteria. The largest number of articles examined the impact of COVID-19 on family caregivers' mental health, followed by its impact on family relationships. The pandemic reportedly worsened family relationships and functioning, increasing domestic violence. The increased burden of caregiving for children and older adults due to COVID-19 was a risk factor for poor physical, psychological, and social health among family caregivers. The workplace environments and health conditions of workers involved with COVID-19 patients affected their family members' physical, psychological, and social health. The social and economic impact of the pandemic could change the internal family system and the permeability of its boundaries, necessitating strategies to maintain an open family system. Additionally, family caregivers are at high risk for poor mental health and need a provision of psychosocial support. Moreover, devising strategies to improve workplace environments and alleviate health issues of workers involved with COVID-19 patients would be crucial for better mental health among their family members.
\end{abstract}

\section{Keywords}

COVID-19, Family Health, Family Well-Being 


\section{Introduction}

A pneumonia of unknown cause, which was later identified as coronavirus disease of 2019 (COVID-19) caused by severe acute respiratory syndrome coronavirus 2 (SARS-CoV-2), was first diagnosed in Wuhan [1]. The World Health Organization declared COVID-19 a global pandemic on March 11, 2020 [2]. In the context of this pandemic, governments worldwide have taken measures to prevent and control COVID-19 infection [3], which has had a serious impact not only on the society, economy, and medical system, but also on individuals who are surrounded by these systems.

The COVID-19 pandemic is considered a type of Chemical, Biological, Radiological Nuclear, and high-yield Explosive (CBRNE) disaster [4]. A CBRNE disaster includes the uncontrolled release of hazardous chemicals, biological agents, or radioactive substances into the environment, potentially combined with explosions that cause widespread damage [5]. CBRNE disasters cause social disruption (e.g., discrimination, slander, bullying, increase in false rumors and misinformation, dissatisfaction, and discontent with the government and community), economic deterioration (e.g., job loss, decline in economic activities, and shortage of supplies), limitations and changes in individual behaviors (e.g., avoidance of travel and going out, and increase in alcohol and tobacco use), and poor public and individual health (e.g., damage to the medical system) [6] [7]. A systematic review by Brooks et al. included 24 quantitative and qualitative studies across 10 countries, where quarantine was imposed owing to direct or potential exposure to SARS, Ebola virus, H1N1 influenza, Middle East Respiratory Syndrome (MERS), equine influenza, or outbreaks of infections. The review showed that quarantine particularly deteriorated individual mental health (e.g., by increasing anxiety, depression, irritability, posttraumatic stress, and emotional exhaustion) [8].

Although previous studies have emphasized the psychological effects of infection outbreaks and their subsequent quarantine on individuals, they could also influence well-being in a family composed of individuals interacting with each other. According to the family systems theory, the family as a system exists in a hierarchical structure within society, with the family and its members falling at a lower level [9]. Thus, changes in a society consequently affect families and their members hierarchically [9]. During the H1N1 influenza pandemic, being a healthcare worker involved with a patient, or hospitalization of a family member infected with the virus complicated the relationship between family members due to its associated health risks [10]. Considering all the prior studies on similar topics, there has been no systematic report on the effects of the COVID-19 pandemic, including measures to prevent and control it, on family health and wellbeing.

This scoping review therefore aimed to clarify the impact of the COVID-19 pandemic on family well-being, while considering the various steps implemented to mitigate its impact. 


\section{Methods}

\subsection{Overview}

Studies exploring the influence of COVID-19 on family well-being were reviewed using the scoping review method of Arksey and O'Malley [11]. We also followed the Preferred Reporting Items for Systematic reviews and Meta-Analyses extension for scoping reviews (PRISMA-ScR) [12].

\subsection{Search Strategy}

A literature search was conducted on MEDLINE and CINAHL using controlled vocabulary terms (i.e., Mesh for MEDLINE and CINAHL Subject Headings for CINAHL). The literature search was conducted in MEDLINE and CINAHL in order to obtain specific suggestions to nursing care. We identified the literature published between January 1, 2020 and August 19, 2021. The terms regarding COVID-19 were "COVID-19" or "SARS-CoV-2" in both MEDLINE and CINAHL. The terms about family were "Family," "Family Characteristics," "Family Relations," "Family Conflict," "Family Health," or "Family Nursing" in MEDLINE; and "Family," "Family Relations," "Family Attitudes," "Patient-Family Relations," "Dysfunctional Family," or "Family Nursing" in CINAHL. Subsequently, the search results of the COVID-19 pandemic were combined with those of family well-being.

\subsection{Study Selection}

Based on previous systematic reviews [13] [14] [15], family well-being included not only family health, happiness, and relations such as couple and parent-child relationships, intimate partner violence (IPV), child abuse and neglect (CAN), and family functioning, but also physical, mental, and social health, and quality of life (QOL) among family members such as family caregivers of patients, children, and older adults. Therefore, this study included the outcomes of both a family as a collective system and its individual members. The titles or abstracts of the relevant studies were screened, following which the full publications of the potentially eligible studies were considered. Studies were excluded if they met the following criteria: 1) not including an abstract, 2) published in non-English, 3) not focusing on the COVID-19 pandemic, 4) not focusing on family well-being, and 5) reviews, recommendations, comments, and editorials. The reference lists of the excluded review articles were inspected to identify additional studies. According to the scoping review methods of Arksey and O'Malley [11] and PRISMA-ScR [12], this review did not assess the methodological quality of the included studies.

\section{Results}

\subsection{Flow of Literature Search and Description of Included Studies}

A total of 923 articles were retrieved from MEDLINE and CINAHL databases 
(Figure 1). Of these, 11 duplicates were excluded. The titles and abstracts of the remaining 902 articles were screened for eligibility, and 783 articles were excluded for the following reasons: 237 articles included no abstract, 39 were published in non-English, 25 did not focus on the COVID-19 pandemic, 465 did not focus on family well-being, and 17 were reviews, recommendations, comments, and editorials. The full publication of the remaining 119 articles was assessed for eligibility, and 94 articles were excluded for the following reasons: one did not focus on the COVID-19 pandemic, 81 did not focus on family well-being, and 12 were reviews, recommendations, comments, and editorials. There was no additional article found through screening the reference lists of the excluded review articles. Finally, 25 articles were included in this scoping review.

Twelve of the 25 identified studies targeted families of individuals with no diseases and disabilities [16] [27], four targeted families of COVID-19 patients and survivors [28] [29] [30] [31], four involved families of individuals with disabilities [32] [33] [34] [35], three included families of children with chronic diseases [36] [37] [38], and two targeted families of workers involved with COVID-19 patients [39] [40] (Table 1). Of the 25 identified studies, 17 used a cross-sectional quantitative design [16] [18] [19] [20] [21] [23] [25] [26] [31]-[36] [38] [39] [40], four used a longitudinal quantitative design [22] [27] [28] [37], two used a qualitative design [29] [30], and two involved mixed methods [17] [24]. Five of the studies were conducted in China [18] [27] [38] [39] [40], three each in the United States of America (USA) [20] [33] [34] and Hong Kong [23] [25] [26], two each in Iran [29] [30] and Switzerland [28] [37], and one each in Albania [21], Bangladesh [19], Brazil [36], Canada [16], Greece [35], Japan [22], Netherlands [24], Saudi Arabia [32], and Spain [17]. One study conducted an online survey around the world, mainly in Europe and North America [31].

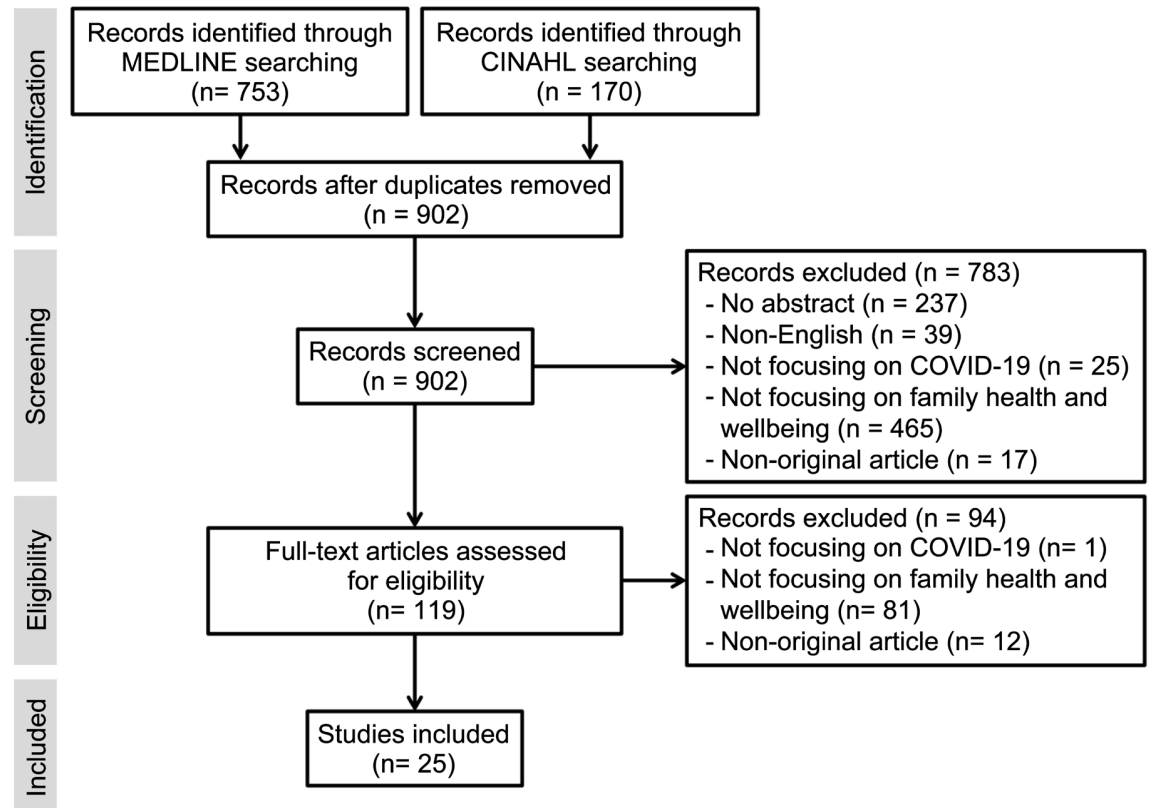

Figure 1. Flowchart of article extraction from the literature search. 
Table 1. Overview of relevant studies on impacts of COVID-19 pandemic on family well-being.

\begin{tabular}{|c|c|c|c|c|c|c|}
\hline $\begin{array}{l}\text { Authors, } \\
\text { country, } \\
\text { and year }\end{array}$ & Design & $\begin{array}{l}\text { Time of } \\
\text { Study }\end{array}$ & Participants & Outcome & Measure & Key findings \\
\hline
\end{tabular}

Families of individuals with no disease and disability

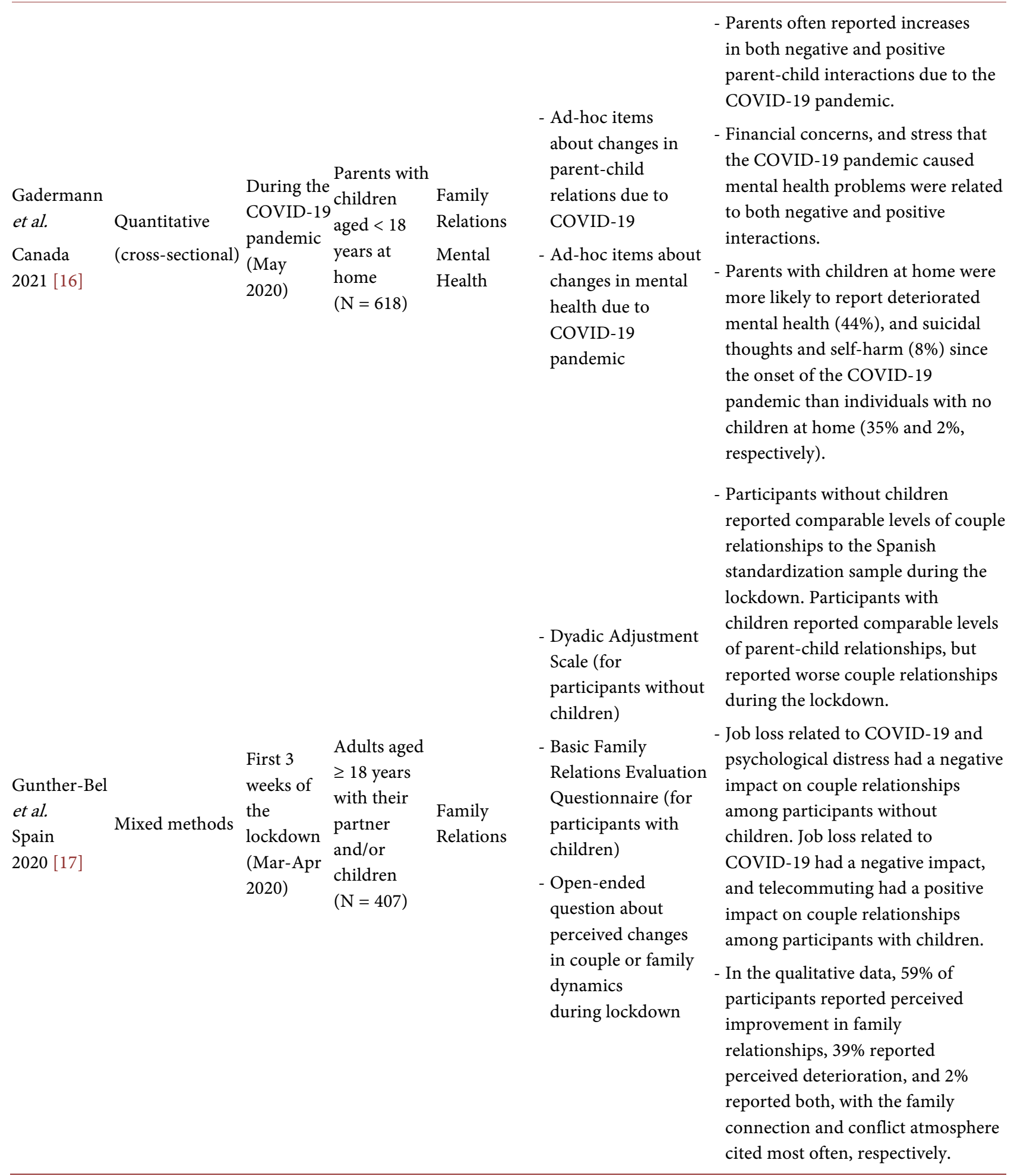




$\begin{array}{llll}\text { Guo et al. } & \text { Quantitative } & \begin{array}{l}\text { During } \\ \text { lockdown individuals }\end{array} & \begin{array}{l}\text { Non-specific } \\ \text { China }\end{array} \\ 2021[18] & \text { (cross-sectional) } & \begin{array}{l}\text { Relations } \\ (\text { Feb 2020) }\end{array} & (\mathrm{N}=24,188)\end{array}$

\begin{tabular}{|c|c|c|c|c|}
\hline Hamadani & & During & $\begin{array}{l}\text { Mothers or } \\
\text { female }\end{array}$ & IPV \\
\hline $\begin{array}{l}\text { et al. } \\
\text { Bangladesh }\end{array}$ & $\begin{array}{l}\text { Quantitative } \\
\text { (cross-sectional) }\end{array}$ & $\begin{array}{l}\text { lockdown } \\
\text { (May-Iune }\end{array}$ & guardians of & Mental \\
\hline 2020 [19] & (cross-sectional) & 2020) & $\begin{array}{l}\text { children } \\
(\mathrm{N}=2417)\end{array}$ & Health \\
\hline
\end{tabular}

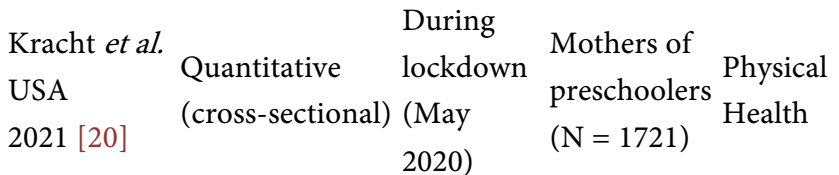

$\begin{array}{lllll}\text { Mechili } \text { et al. } & \text { Quantitative } & 10 \text { days of } & \text { students } & \text { Mental } \\ \text { Albania } & \text { (cross-sectional) } & \begin{array}{ll}\text { lockdown } \\ \text { (Mar-Apr }\end{array} & \text { and their } & \text { Health } \\ & & \text { 2020) } & \text { family } & \\ & & \text { members } & \\ & & (\mathrm{N}=249) & \end{array}$
10 days of students
- Ad-hoc items about family closeness including remote and face-to-face communication with family and family activities such as playing games

- Items based on the WHO multi-country survey tool and specifically addressed emotional, physical, and sexual violence

- Centre for Epidemiologic Studies-Depression Scale

- Generalized Anxiety Scale

- Godin-Shephard Leisure-time Physical Activity Questionnaire (physical activity) Pittsburgh Sleep Quality Index (sleep disturbance)

Bachelor and master After first nursing lockdown $(\mathrm{N}=863)$ (Mar-Apr and their $(\mathrm{N}=249)$ Questionnaire-9 (depression)
- Of participants, $63 \%$ reported more closeness with their families than before the pandemic (such as in network communication, face-to-face family activities, and playing games), while only $8 \%$ reported less closeness with their families.

- Family closeness of participants was increased in areas where COVID-19 was more prevalent. Family closeness of participants with better neighborhood closeness was better than that of participants with worse neighborhood closeness.

- Compared to before the lockdown, more than half of Bangladeshi mothers with experiences of IPV reported that depressive symptoms, and emotional, physical, and sexual violence increased during the lockdown.

- Of participants, $26 \%$ reported mild anxiety, $12 \%$ reported moderate anxiety, $1 \%$ reported severe anxiety, and $99 \%$ reported an increase in anxiety symptoms since the onset of the lockdown.

- Household chaos and stress were negatively related to physical activity and sleep among mothers of preschoolers.

- Stress partially mediated the association of household chaos with physical activity and sleep among mothers of preschoolers.

- Twenty six percent of family members with nursing students indicated moderate to severe - Patient Health symptoms of depression.

- Family members who considered that COVID-19 and quarantine could cause problems on their health, reported elevated levels of depression. 


\begin{tabular}{|c|c|c|c|c|}
\hline $\begin{array}{l}\text { Noguchi } \\
\text { et al. } \\
\text { Japan } \\
2021[22]\end{array}$ & $\begin{array}{l}\text { Quantitative } \\
\text { (longitudinal) }\end{array}$ & $\begin{array}{l} \\
\text { Before } \\
\text { (Mar 2020) } \\
\text { and after } \\
\text { (Oct 2020) } \\
\text { lockdown }\end{array}$ & $\begin{array}{l}\text { Family } \\
\text { caregivers } \\
\text { and } \\
\text { non-family } \\
\text { caregivers } \\
\text { who were } \\
\text { community- } \\
\text { dwelling } \\
\text { older adults } \\
\text { aged } \geq 65 \\
\text { years } \\
(\mathrm{N}=957)\end{array}$ & $\begin{array}{l}\text { Mental } \\
\text { Health }\end{array}$ \\
\hline $\begin{array}{l}\text { Sit et al. } \\
\text { Hong Kong } \\
2021[23]\end{array}$ & $\begin{array}{l}\text { Quantitative } \\
\text { (cross-sectional) }\end{array}$ & $\begin{array}{l}\text { During } \\
\text { COVID-19 } \\
\text { pandemic } \\
\text { (May } \\
2020 \text { ) }\end{array}$ & $\begin{array}{l}\text { Adults aged } \\
\geq 18 \text { years } \\
\text { with one or } \\
\text { more family } \\
\text { members } \\
(\mathrm{N}=4890)\end{array}$ & $\begin{array}{l}\text { Family } \\
\text { Health } \\
\text { Family } \\
\text { Happiness } \\
\text { Family } \\
\text { Relations }\end{array}$ \\
\hline
\end{tabular}

Parents aged

$\geq 18$ years

$(\mathrm{N}=290)$

and children

aged $3-18$

years

$(\mathrm{N}=261)$ in

the same

families with

high risk of

IPV and/or

CAN for

Before (Jan quantitative

Tierolf et al. 2020) and study, and

Netherlands Mixed Methods during parents aged 2021 [24]

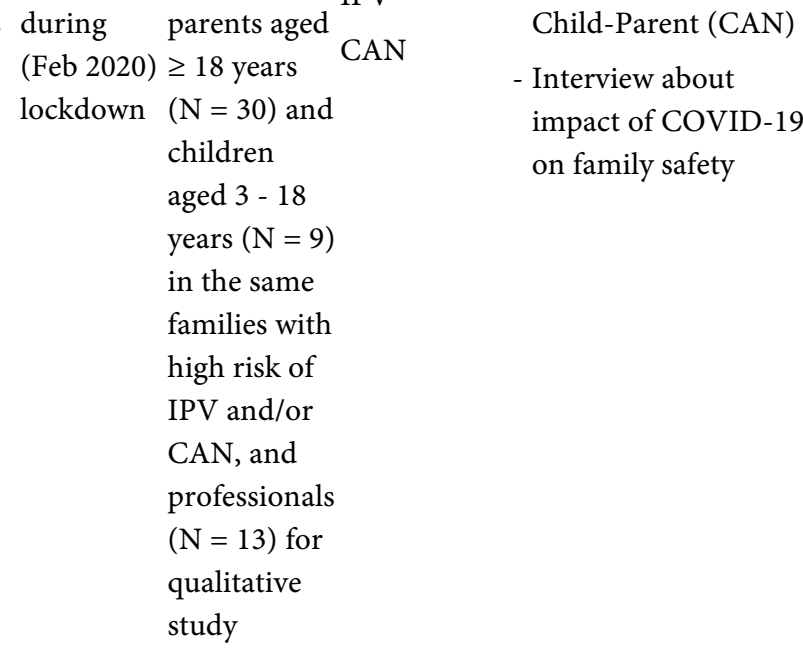
Child-Parent (CAN)

- Interview about

on family safety

- Family caregivers were more likely to have the incidence (having no depression symptoms before lockdown, but having them after lockdown) or persistence (having depression based on
- Items about a previous study depression symptoms both before and after lockdown) of depressive symptoms than non-family caregivers.

- Caregivers with increased burden during the lockdown experienced higher incidence or persistence of depressive symptoms.

- Items about family health, harmony, and happiness based on a previous study

- Ad-hoc items about increase in negative emotions among family members and Fear of COVID-19 was not associated with family happiness, family health, and family harmony, but was associated with increased family conflicts and negative emotions among family members. family conflict

\footnotetext{
- No difference was found in the frequencies and severities of IPV and CAN between families before and during the lockdown, but half of the families had frequent and serious violence (more than 22 incidents of IPV and/or CAN per year, and more than two incidents of
- Most families stated that the COVID-19 pandemic often caused stress and tension in the family, further promoting IPV and CAN.

- Conflict Tactics Scale impact of COVID-19 severe IPV). 
- The prevalence of perceived benefits of COVID-19 on family

- Ad-hoc items about family physical health and family hygiene

- Ad-hoc items about family mental health including family negative and positive emotion, and family happiness

Ad-hoc items about family relations including family harmony and family's ability to cope with difficulties

Family

Health

Family

et al.

Hong Kong 2020 [26]

(cross-sectional) pandemic

Happiness Family Relations (Apr 2020) $(\mathrm{N}=1501)$

physical health, mental health, and

relations was $19 \%, 7 \%$, and $14 \%$, respectively. The most common perceived benefits were improved family hygiene in family physical health, increased family positive emotion in family mental health, and increased family's ability to cope with difficulties in family relations.

- The prevalence of perceived harms of COVID-19 on family physical health, mental health, and relations were $2 \%, 38 \%$, and $19 \%$, respectively. The most commonly perceived harms were poorer family physical health, increased family negative emotion in family mental health, and decreased family harmony in family relations.

- Personal preventive behaviors such as washing hands and wearing mask were positively related to family happiness, family health, and family harmony.

- Pregnant women during the COVID-19 pandemic reported lower levels of family cohesion and

- Symptom Check higher levels of conflict and List-90 Revised independence compared to before

Before Pregnant (Mar-Dec women 2019) and $(\mathrm{N}=2657$
Xie et al. China 2021 [27]
Quantitative (longitudinal) during before the

(Jan-Aug pandemic 2020) and $\mathrm{N}=68$ COVID-19 during the pandemic pandemic)
Family

Functioning Physical Health Mental Health (depression, anxiety, the pandemic.

and somatization) - Pregnant women during the

- Pittsburgh Sleep

Quality Index (Sleep disturbance) COVID-19 pandemic were more likely to report sleep disturbance, depression, anxiety, and somatization, compared to before the pandemic. Scale (Family Functioning)
- Family cohesion was a protective factor for depression, anxiety, and somatization, whereas family conflict was a risk factor.

Families of COVID-19 patients and survivors

\begin{tabular}{lllll}
\hline $\begin{array}{l}\text { Beck et al. } \\
\text { Switzerland } \\
2021[28]\end{array}$ & $\begin{array}{l}\text { Quantitative } \\
\text { (longitudinal) }\end{array}$ & $\begin{array}{l}\text { COVID-19 patients after Mental } \\
\text { pandemic hospital Health } \\
\text { (Mar-Jun discharge }\end{array}$ & $\begin{array}{l}\text { - Hospital Anxiety and } \\
\text { Depression Scale } \\
\text { (anxiety and } \\
\text { depression) }\end{array}$ & $\begin{array}{l}\text { - Of the relatives of COVID-9 } \\
\text { patients, 16\% had moderate } \\
\text { symptoms of anxiety and 15\% had } \\
\text { moderate symptoms of depression. }\end{array}$ \\
\hline
\end{tabular}




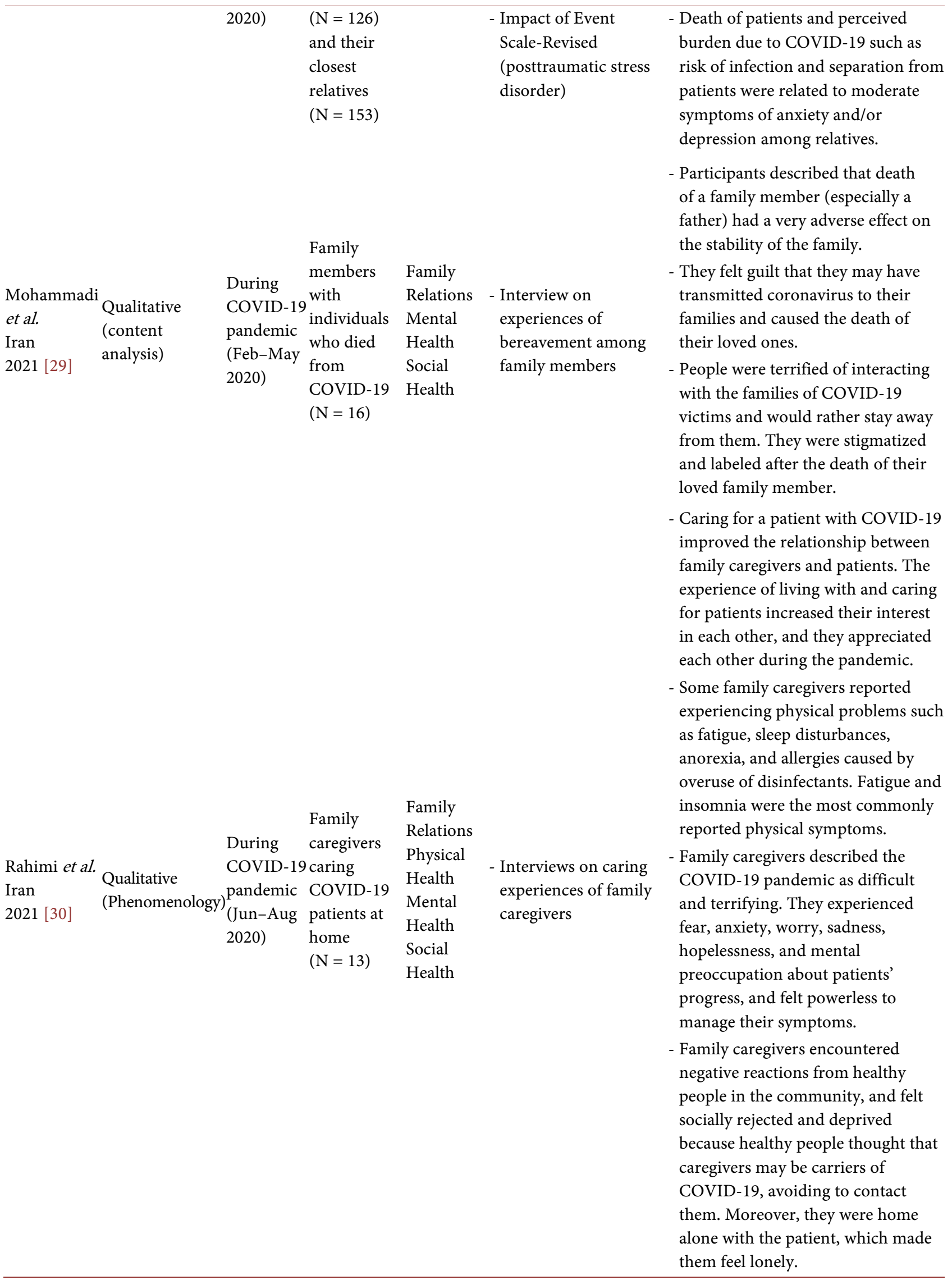


COVID-19

survivors

after average

13 weeks

since

COVID-19

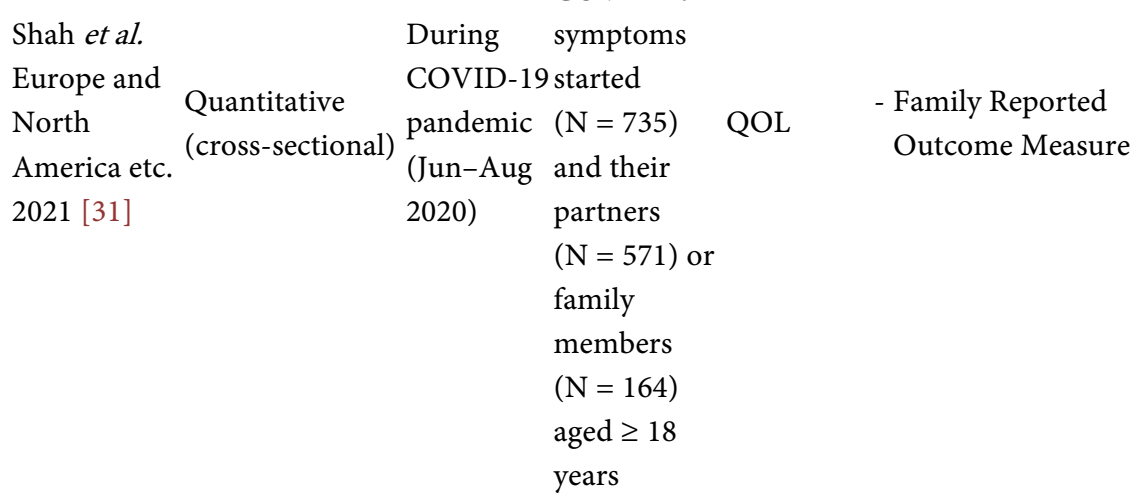

- Partners and family members reported that the poor dimension of the Family Reported Outcome Measure measuring their QOL was feeling worried, followed by the dimension of family activities, frustration, holiday, and sex life.

- Partners and family members with a COVID-19 history experienced a greater impact on eating habits, work and study, family activities, holiday, sex life, and sleep than those with no history.

Families of individuals with disabilities

- Of parents, $94 \%$ reported that

Parents of children with During autism Alhuzimi $\quad$ Quantitative 2021 [32] COVID-19 spectrum

Mental ) pandemic disorder $\begin{aligned}(\text { Jun 2020) } & (\text { ASD }) \text { aged } \\ & \leq 18 \text { years } \\ & (\mathrm{N}=150)\end{aligned}$

Family caregiver of individuals with physical and cognitive/ memory During problems,
Beach et al.

USA 2021 [33]
Quantitative COVID-19 and pandemic behavioral, (Apr-May emotional, 2020) or developmental disorder $(\mathrm{N}=576)$ and non-family caregivers $(\mathrm{N}=2933)$
- Patient-Reported

Physical Outcomes

Health Measurement

Mental Information System

Health short forms (anxiety,

Social depression, fatigue,

Health sleep disturbance, and social participation) parenting stress increased, and 79\% reported that psychological distress was impacted due to the present COVID-19 situation.

- More severe ASD behaviors in comparison to the pre-COVID-19 status increased parenting stress and psychological distress, while a higher frequency and usefulness of ASD support decreased parenting stress and psychological distress.

- Family caregivers reported more anxiety, depression, fatigue and sleep disturbance, and less ability to participate in social activities than non-family caregivers.

- Family caregivers who reported a greater impact of COVID-19 on their caregiving had more anxiety, depression, fatigue and sleep disturbance, and less social participation than family caregivers who reported less impact. 


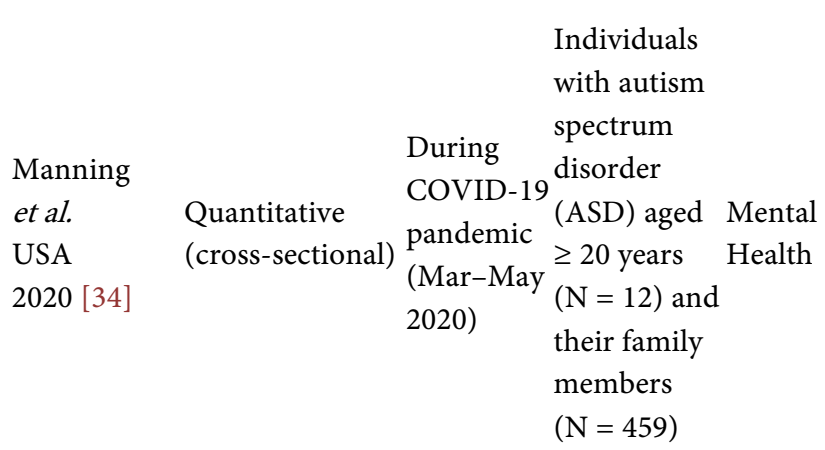

Tsibidaki

Greece 2021 [35]
Quantitative (cross-sectional) lock
Second

and third $(\mathrm{N}=35)$ in

students

$(\mathrm{N}=26)$ and

week of families with Mental

lockdown one or more Health

(Mar-Apr members

2020) with special

educational

needs and

disability

- Family members of individuals with ASD had high levels of stress caused by COVID-19 restrictions.

- Family members reported the following stressors: worry about an individual with ASD being home all the time (55\%), concern about

- Ad-hoc item about stress in families caused by the COVID-19 restrictions

\section{of} separation from an individual with
ASD (5\%).

- ASD severity increased stress caused by COVID-19 restrictions among family members.

- Parents reported higher levels of state anxiety and resilience, and reported lower levels of trait anxiety than university students.

- State-Trait Anxiety Inventory (anxiety)

- Higher levels of self-efficacy and resilience improved state and trait anxiety among both university students and parents.
- The proportion of having mental health disorders during social distancing was higher in family caregivers of children with type 1 diabetes aged $<12$ years compared to those of children without diabetes aged $<12$ years.

- Self-Reporting Questionnaire (mental - Family caregivers of children with health disorders)

- Ad-hoc items about pandemic-related emotional burden and diabetes-specific emotional burden related to diabetes care type 1 diabetes reported more pandemic-related emotional burden compared to family caregivers of those without diabetes.

- Regarding psychological burden related to diabetes care among family caregivers of children with type1 diabetes, $41 \%$ reported discontent in care sharing, 36\% reported discontent in support, $42 \%$ reported discontent in appreciation, $48 \%$ reported exhaustion, and $76 \%$ reported guilt problems. 


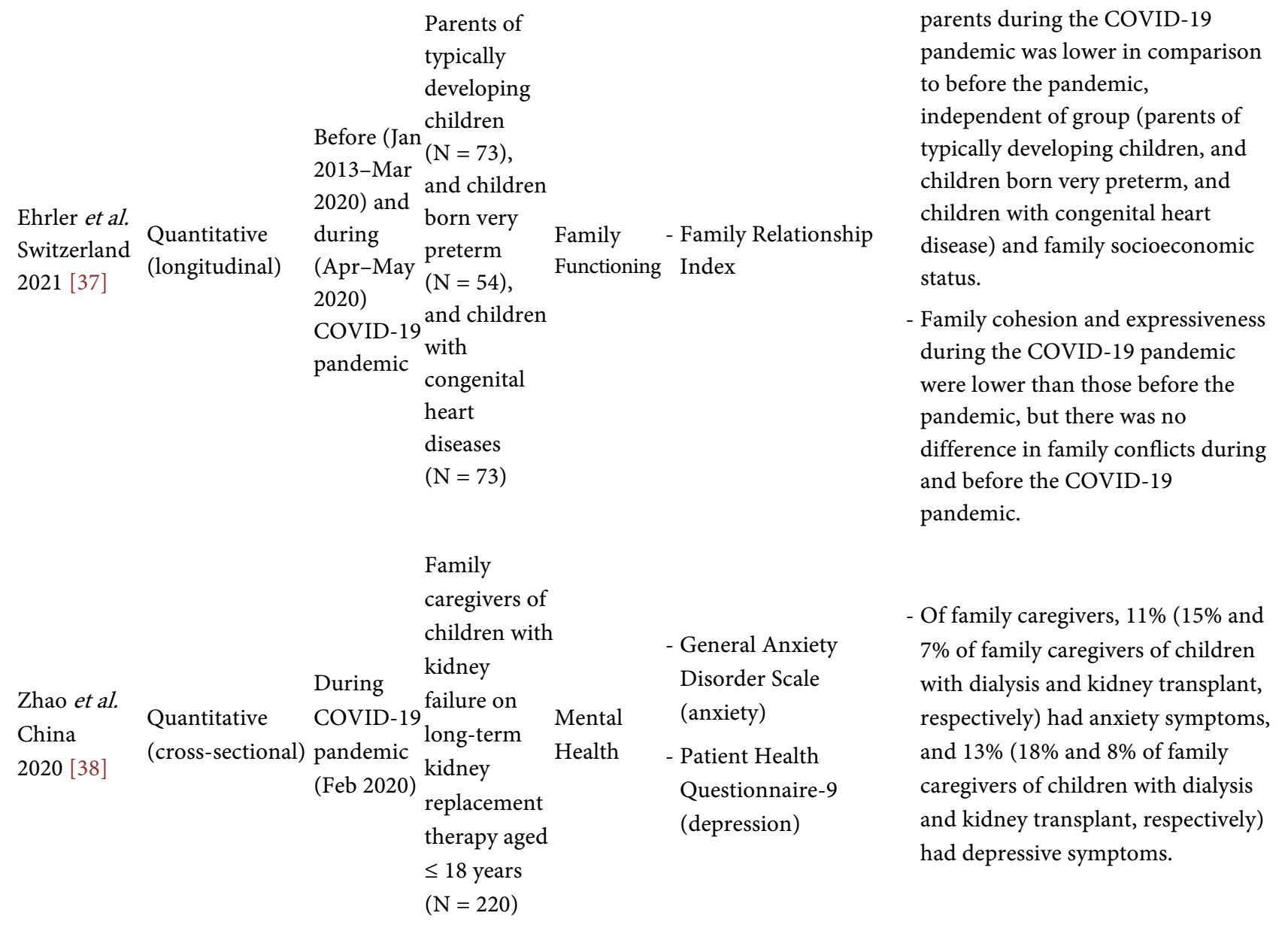

Families of workers involved COVID-19 patients

\begin{tabular}{|c|c|c|c|c|c|c|}
\hline $\begin{array}{l}\text { Feng et al. } \\
\text { China } \\
2020[39]\end{array}$ & $\begin{array}{l}\text { Quantitative } \\
\text { (cross-sectional) }\end{array}$ & $\begin{array}{l}\text { During } \\
\text { COVID-19 } \\
\text { pandemic } \\
\text { (Feb 2020) }\end{array}$ & $\begin{array}{l}\text { Family } \\
\text { members of } \\
9 \text { front-line } \\
\text { rescue } \\
\text { workers } \\
(\mathrm{N}=671)\end{array}$ & $\begin{array}{l}\text { Physical } \\
\text { Health } \\
\text { Mental } \\
\text { Health }\end{array}$ & $\begin{array}{l}\text { - Generalized Anxiety } \\
\text { Disorder-7 (anxiety) } \\
\text { - Patient Health } \\
\text { Questionnaire-2 } \\
\text { (depression) } \\
\text { - Primary Care } \\
\text { Posttraumatic Stress } \\
\text { Disorder Screen for } \\
\text { DSM-5 (posttraumatic } \\
\text { stress) } \\
\text { - Items extracted from } \\
\text { Patient Health } \\
\text { Questionnaire-9 (sleep } \\
\text { disturbance and } \\
\text { suicidal thought) }\end{array}$ & $\begin{array}{l}\text { - Of the family members, } 55 \% \\
\text { reported sleep disturbance, } 49 \% \text { had } \\
\text { mild or more anxiety symptoms, } \\
12 \% \text { reported clinically significant } \\
\text { depression symptoms, } 10 \% \text { might } \\
\text { have posttraumatic stress, and } 8 \% \\
\text { had suicidal thoughts. } \\
\text { - Family members who were more } \\
\text { worried about the safety of } \\
\text { front-line rescue workers had sleep } \\
\text { disturbance and more posttraumatic } \\
\text { stress than those who were less } \\
\text { worried. } \\
\text { - Family members who were more } \\
\text { worried about physical condition of } \\
\text { front-line rescue workers had sleep } \\
\text { disturbance and more depressive } \\
\text { symptoms than family members } \\
\text { who were less worried. } \\
\text { - Family members who were more }\end{array}$ \\
\hline
\end{tabular}




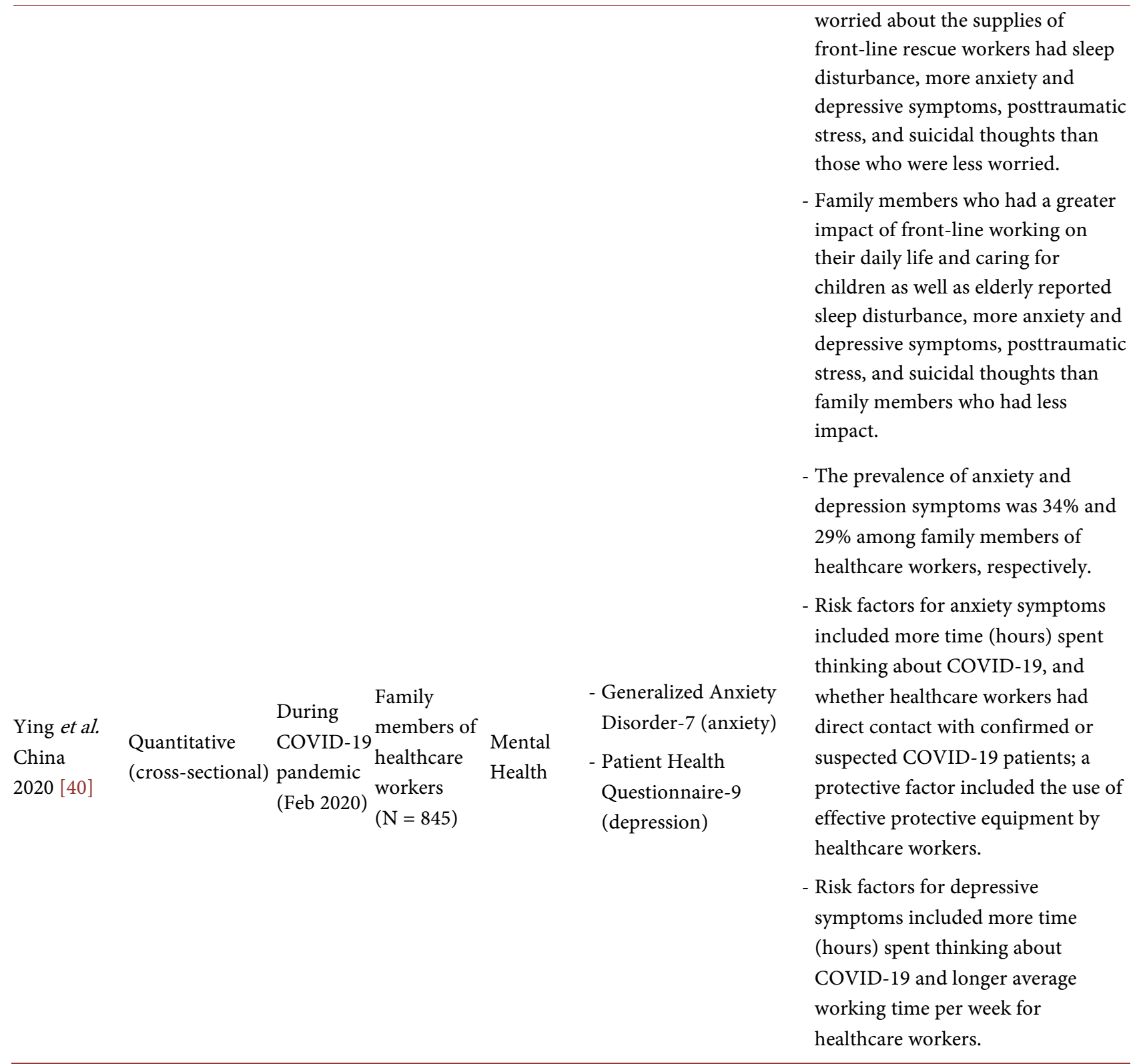

Three studies focused on family health [23] [25] [26], two on family happiness [25] [26], eight on family relations [16] [17] [18] [23] [25] [26] [29] [30], two on family functioning [27] [37], and two on IPV and/or CAN [19] [24]. In addition, five studies focused on family caregivers' physical health [20] [27] [30] [33] [39], 16 on family caregivers' mental health [16] [19] [21] [22] [27] [28] [29] [30] [32] [33] [34] [35] [36] [38] [39] [40], three on family caregivers' social health [29] [30] [33], and one on family caregivers' QOL [31].

\subsection{Family Health and Happiness}

All studies exploring family health and happiness were conducted in Hong Kong [23] [25] [26]. In the study by Wong et al. [25], families perceived certain benefits of COVID-19 in terms of physical health (e.g., improved family hygiene and 
improved family physical health), and harm to mental health (e.g., increased family negative emotion and decreased family happiness). In the studies by Sit et al. and Wong et al. that used the same items about family health and happiness, fear of COVID-19 was negatively associated [23], and personal preventive behaviors such as washing hands and wearing masks were positively associated with perceived family health and happiness among family members in Hong Kong [26].

\subsection{Family Relations}

Families reported that while family and parent-child relationships worsened during the COVID-19 pandemic, they also improved in certain instances [16] [17] [18] [25], with families reporting improved family relationships rather than worsened ones in some studies [16] [25]. Members of families that engaged in personal preventive behaviors perceived that their families were more harmonious than those who did not [26]. Telecommuting was associated with couple relationships in Spanish families [17]. In contrast, job loss and financial concerns caused by the COVID-19 pandemic, fear of infection with COVID-19, and stress that the pandemic exacerbates an existing mental health problem, worsened couple, parent-child, and family relationships (e.g., increased harsh words, conflicts and yelling/shouting) [16] [23].

Two qualitative studies exploring family relationships among families of Covid-19 patients were conducted in Iran [29] [30]. When family caregivers lived with and provided care to COVID-19 patients, they became more interested in and appreciative of each other [30]. Family members described that the death of a member, especially a father, had a very adverse effect on the stability of their family [29].

\subsection{Family Functioning}

Compared to before the pandemic, Chinese pregnant women reported less family cohesion and more family conflicts and independence during COVID-19 [27]. Similarly, family cohesion and expressiveness during the COVID-19 pandemic was lower than before among parents with typically developing children, children born very preterm, or children with congenital heart diseases in Switzerland [37].

\subsection{IPV and CAN}

No difference was found in the frequencies and severities of IPV and CAN before and during the lockdown among families with high risk of IPV and/or CAN in the Netherlands, but half of them reported frequent and serious violence during the containment [24]. Compared to before the lockdown, more than half of Bangladeshi mothers with experiences of IPV reported that emotional, sexual, and physical (moderate and severe) violence increased during the confinement [19]. 


\subsection{Family Members' Physical Health}

Chinese pregnant women reported sleep disturbance more frequently during the COVID-19 pandemic than before it [27]. Household chaos and stress related to the lockdown were negatively related to sleep time and physical activities among parents of preschoolers in the USA [20].

Family members providing care for COVID-19 patients at home reported sleep disturbance and fatigue as the most common physical problems [30]. Family caregivers of individuals with disabilities had more fatigue and sleep disturbance than non-family caregivers, and these symptoms worsened with increased caregiving burden related to COVID-19 [33].

More than half of the Chinese family members of front-line rescue workers had sleep disturbance with increased worry regarding the workers' physical condition and access to of supplies; a greater impact of front-line work on their daily lives was associated with more sleep disturbance [39].

\subsection{Family Members' Mental Health}

The COVID-19 pandemic and the subsequent lockdown increased psychological problems such as depression, anxiety, and somatic symptoms among pregnant women, and parents with infants or children aged $<18$ years at home [16] [19] [27]. Among family members with nursing students, $26 \%$ indicated moderate to severe symptoms of depression after the first 10 days of lockdown associated with COVID-19 [21]. Eight percent of parents with children aged $<18$ years at home reported suicidal ideation or self-harm during the pandemic, which was at a higher proportion than for parents without children at home (2\%) [16]. Parenting for children, alongside caregiving and its increased burden for older adults during COVID-19 aggravated parents' and family caregivers' mental health [16] [22]. The belief that COVID-19 and the lockdown phase increased health problems influenced the worsening of depression among family members of nursing students [21]. Family cohesion perceived by pregnant women decreased their anxiety, depression, and somatization symptoms, while family conflict increased the perception of these symptoms [27].

Qualitative studies found that family members who had COVID-19 patients or experienced their deaths, described COVID-19 as difficult and terrifying, feeling fear, anxiety, worry, sadness, and hopelessness; they also reported negative preoccupation about patients' progress, feeling powerless to manage their symptoms and guilt that they may have transmitted the virus to their families, causing their deaths [29] [30]. Sixteen percent of family members with COVID19 patients had anxiety, and 15\% had depression [28]. The burden associated with COVID-19, such as the risk of infection and isolation from patients, and their death increased depression and anxiety [28].

Family members of individuals with disabilities reported aggravation of depression, anxiety, parenting stress, and psychological distress due to the COVID19 pandemic and its subsequent lockdown [32] [33] [34] [35]. Increased severity of disabilities [32] [34], caregiving burden [33], and lack of support [32] for in- 
dividuals with disabilities were negatively related to mental health. In addition, during the COVID-19 pandemic and its subsequent lockdown, family caregivers of children with type 1 diabetes or kidney failure reported depression, anxiety, and pandemic-related emotional burden (e.g., feeling worried and afraid of being infected with the virus) [36] [38].

Among family members of workers involved with COVID-19 patients, 34\% $49 \%$ reported anxiety, $12 \%$ - $29 \%$ reported depression, $10 \%$ reported posttraumatic stress, and $8 \%$ reported suicidal ideation [39]. Worries about the safety and physical condition of workers, lack of supplies for workers, a greater impact of their job on their daily life, more time spent thinking about COVID-19, and longer working time of workers deteriorated psychological problems among family members [39] [40].

\subsection{Family Members' Social Health}

Family caregivers who had COVID-19 patients or experienced their deaths described that healthy people in the community were terrified of interacting with them, and would rather stay away from them, making them feel socially rejected and lonely [29] [30].

During the pandemic, family caregivers of individuals with disabilities reported less ability to participate in social activities than non-family caregivers. Those who reported a greater impact of COVID-19 on their caregiving also had less social participation than family caregivers who reported less impact [33].

\subsection{Family Members' QOL}

Partners and family members of COVID-19 survivors reported that the poor dimension of the Family Reported Outcome Measure measuring their QOL was feeling worried, followed by the dimension of family activities, frustration, holiday, and sex life [31]. Partners and family members with a COVID-19 history experienced a greater impact on eating habits, work and study, family activities, holiday, sex life, and sleep than those with no history.

\section{Discussion}

This scoping review provides an overview of the current state of knowledge regarding the impact of the COVID-19 pandemic on family well-being. Twenty-five studies included in this review covered a variety of families, regardless of whether they had diseases and disabilities, and examined the association of COVID-19 with the health and well-being of whole families as well as individual members. This review suggested that due to the COVID-19 pandemic, families concurrently perceived deterioration of family relationships and experienced poor family functioning, and an increase in IPV and CAN. Family members also reported an impairment in physical, mental, and social health due to the pandemic, with an increase in caregiving burden for family members being negatively associated with physical, mental, and social health among family members. 
Moreover, the work environment and condition of workers involved with Covid-19 patients worsened their family members' physical, mental, and social health.

From the viewpoint of the family systems theory [9], pandemic-related changes in a society as the higher system and a family member as the lower system would affect a family. Decline in economic activities due to COVID-19 could lead to job loss of family members, subsequently worsening the family's economic status. In addition, encouragement of telework and the closing of schools could make family members spend more time together at home, potentially altering the roles each individual plays in their families. Since family members of COVID-19 patients experienced isolation and bereavement, their family structure could change. Such changes in the family's internal system would negatively affect family relationships (e.g., conflicts and tension among family members) and family functioning (e.g., lower family cohesion), which may result in increased IPV and CAN.

The COVID-19 pandemic and its subsequent lockdown deteriorated interactions between family members and the community, such as health care providers and neighbors. This reduced exchange of information and support between family members and their community, indicating reduced permeability at the boundaries of the family system [41]. A closed family system, which implies low permeability at the boundaries of the family system, would make it more difficult to introduce support into a family during the COVID-19 pandemic, as compared to before it. Strategies maintaining an open family system are therefore needed to improve family relationships, functioning and happiness, even during a pandemic.

The COVID-19 pandemic is considered a CBRNE disaster, and its impact on individual mental health has received attention [4] [5] [8]. In this scoping review, the largest number of studies revealed a negative impact of COVID-19 on family members' mental health [16] [19] [21] [22] [27] [28] [29] [30] [32] [33] [34] [35] [36] [38] [39] [40]. In addition, caregiving for family members, and its increased burden due to COVID-19, were negatively associated with family caregivers' mental health [16] [22] [33] [39]. During the outbreak of an infectious disease, family members in caregiving roles would be at high risk for the deterioration of their mental health, requiring psychosocial support. Moreover, complex grief and posttraumatic stress were reportedly associated with poor social health in adults who lost a loved one infected with COVID-19, such as friends [42]. Thus, the deterioration of family members' mental health may spill over to poor physical and social health. Therefore, preventing deterioration in family members' mental health may be the first step in maintaining family well-being.

The families of workers involved with COVID-19 patients also had poor mental health [39] [40]. In addition, workplace environments and the health status of these workers affected their family members' physical, psychological, and social health [39] [40]. A CBRNE disaster has negative impacts on the health care system, such as shortage of human resources and supplies, which would place the 
workers involved with COVID-19 patients in harsh working conditions, compromising their health [6] [7]. Thus, appropriate allocation of medical resources by a government and monitoring condition of workers involved with COVID-19 patients by medical institutions could improve health condition of both workers and their family members.

This scoping review had some limitations. First, most studies included in this review conducted cross-sectional quantitative and qualitative research, while few used longitudinal quantitative research. This study insufficiently indicated evidence of the impact of the COVID-19 pandemic on family well-being. Second, the studies included in this review targeted a variety of families and investigated many types of outcomes on family well-being. Moreover, these studies were conducted in countries with different policies to prevent the COVID-19 pandemic and a variety of medical and social welfare systems. This made it difficult to compare the results of each study. Finally, all studies in this review were conducted in 2020, demonstrating only short-term effects of the pandemic on family well-being. Therefore, the long-term impact of COVID-19 on family well-being should be investigated in future research.

In conclusion, this scoping review suggested that the COVID-19 pandemic and its subsequent lockdown were negatively associated with family well-being, including family relations and their mental and physical health, among various types of families. Considering a future pandemic of infectious disease, nurses need to develop strategies to maintain families' open systems during lockdowns and social distancing measures, while improving family members' mental health.

\section{Funding}

This study was supported by a JSPS KAKENHI Grant-in-Aid for Young Scientists (Grant Number 19K19639).

\section{Authors' Contributions}

The author (TS) conceptualized and designed the study, screened the literature for inclusion and exclusion, qualitatively synthesized the results of eligible literature, and interpreted the study findings. The author also drafted and critically reviewed the manuscript, approved the final version of the manuscript, and agreed to be accountable for all aspects of the work in ensuring that questions related to the accuracy or integrity of any part of the work are appropriately investigated and resolved.

\section{Conflicts of Interest}

The author declares no conflicts of interest regarding the publication of this paper.

\section{References}

[1] World Health Organization (2020) Pneumonia of Unknown Cause-China. 
https://www.who.int/emergencies/disease-outbreak-news/item/2020-DON229

[2] World Health Organization (2020, March 11) WHO Director-General's Opening Remarks at the Media Briefing on COVID-19-11 March 2020.

https://www.who.int/director-general/speeches/detail/who-director-general-s-openi ng-remarks-at-the-media-briefing-on-covid-19---11-march-2020

[3] World Health Organization (2020) A Guide to WHO's Guidance on COVID-19. https://www.who.int/news-room/feature-stories/detail/a-guide-to-who-s-guidance

[4] Shigemura, J., Ursano, R.J., Morganstein, J.C., Kurosawa, M. and Benedek, D.M. (2020) Public Responses to the Novel 2019 Coronavirus (2019-nCoV) in Japan: Mental Health Consequences and Target Populations. Psychiatry and Clinical Neurosciences, 74, 281-282. https://doi.org/10.1111/pcn.12988

[5] Shigemura, J., Terayama, T., Kurosawa, M., Kobayashi, Y., Toda, H., Nagamine, M., et al. (2021) Mental Health Consequences for Survivors of the 2011 Fukushima Nuclear Disaster: A Systematic Review. Part 1: Psychological Consequences. CNS Spectrum, 26, 14-29. https://doi.org/10.1017/S1092852920000164

[6] Fullerton, C.S., Ursano, R.J., Weisaeth, L. and Raphael, B. (2017) Public Health and Disaster Psychiatry. In: Ursano, R.J., Fullerton, C.S., Weisaeth, L. and Raphael, B., Eds., Textbook of Disaster Psychiatry, Cambridge University Press, Cambridge, 325-340. https://doi.org/10.1017/9781316481424.023

[7] Morganstein, J.C., Fullerton, C.S., Ursano, R.J., Donato, D. and Holloway, H.C. (2017) Pandemics: Health Care Emergencies. In: Ursano, R.J., Fullerton, C.S., Weisaeth, L. and Raphael, B., Eds., Textbook of Disaster Psychiatry, Cambridge University Press, Cambridge, 270-284. https://doi.org/10.1017/9781316481424.019

[8] Brooks, S.K., Webster, R.K., Smith, L.E., Woodland, L., Wessely, S., Greenberg, N., et al. (2020) The Psychological Impact of Quarantine and How to Reduce It: Rapid Review of the Evidence. Lancet, 395, 912-920. https://doi.org/10.1016/S0140-6736(20)30460-8

[9] Friedman, M., Bowden, V. and Jones, E. (2002) Family Nursing: Research, Theory, and Practice. 5th Edition, Prentice Hall/Pearson Education, Upper Saddle River.

[10] Sprang, G. and Silman, M. (2013) Posttraumatic Stress Disorder in Parents and Youth after Health-Related Disasters. Disaster Medicine and Public Health Preparedness, 7, 105-110. https://doi.org/10.1017/dmp.2013.22

[11] Arksey, H. and O’Malley, L. (2005) Scoping Studies: Towards a Methodological Framework. International Journal of Social Research Methodology, 8, 19-32. https://doi.org/10.1080/1364557032000119616

[12] Tricco, A.C., Lillie. E., Zarin, W., O’Brien, K.K., Colquhoun, H., Levac, D., et al. (2018) PRISMA Extension for Scoping Reviews (PRISMA-ScR): Checklist and Explanation. Annals of Internal Medicine, 169, 467-473. https://doi.org/10.7326/M18-0850

[13] Krys, K., Capaldi, C.A., Zelenski, J.M., Park, J., Nader, M., Kocimska-Zych, A., et al. (2021) Family Well-Being Is Valued More than Personal Well-Being: A FourCountry Study. Current Psychology, 40, 3332-3343. https://doi.org/10.1007/s12144-019-00249-2

[14] Prime, H., Wade, M. and Browne, D. (2020) Risk and Resilience in Family WellBeing during the COVID-19 Pandemic. American Psychologist, 75, 631-643. https://doi.org/10.1037/amp0000660

[15] Sano, Y., Mammen, S. and Houghten, M. (2021) Well-Being and Stability among Low-Income Families: A 10-Year Review of Research. Journal of Family and Economic Issues, 42, 107-117. https://doi.org/10.1007/s10834-020-09715-7 
[16] Gadermann, A.C., Thomson, K.C., Richardson, C.G., Gagné, M., McAuliffe, C., Hirani, S., et al. (2021) Examining the Impacts of the COVID-19 Pandemic on Family Mental Health in Canada: Findings from a National Cross-Sectional Study. BMJ Open, 11, Article ID: e042871. https://doi.org/10.1136/bmjopen-2020-042871

[17] Günther-Bel, C., Vilaregut, A., Carratala, E., Torras-Garat, S. and Pérez-Testor, C. (2020) A Mixed-Method Study of Individual, Couple, and Parental Functioning during the State-Regulated COVID-19 Lockdown in Spain. Family Process, 59, 1060-1079. https://doi.org/10.1111/famp.12585

[18] Guo, X., Li, J., Gao, Y., Su, F. and Xue, B. (2021) Influence of Major Public Health Emergencies on Family Relationship and Humanistic Geographical Characteristics of China. International Journal of Environmental Research and Public Health, 18, Article No. 3879. https://doi.org/10.3390/ijerph18083879

[19] Hamadani, J.D., Hasan, M.I., Baldi, A.J., Hossain, S.J., Shiraji, S., Bhuiyan, M.S.A., et al. (2020) Immediate Impact of Stay-at-Home Orders to Control COVID-19 Transmission on Socioeconomic Conditions, Food Insecurity, Mental Health, and Intimate Partner Violence in Bangladeshi Women and Their Families: An Interrupted Time Series. Lancet Global Health, 8, e1380-e1389. https://doi.org/10.1016/S2214-109X(20)30366-1

[20] Kracht, C.L., Katzmarzyk, P.T. and Staiano, A.E. (2021) Household Chaos, Maternal Stress, and Maternal Health Behaviors in the United States during the COVID-19 Outbreak. Women's Health, 17, 1-10. https://doi.org/10.1177/17455065211010655

[21] Mechili, E.A., Saliaj, A., Kamberi, F., Girvalaki, C., Peto, E., Patelarou, A.E., et al. (2021) Is the Mental Health of Young Students and Their Family Members Affected During the Quarantine Period? Evidence from the COVID-19 Pandemic in Albania. Journal of Psychiatric and Mental Health Nursing, 28, 317-325. https://doi.org/10.1111/jpm.12672

[22] Noguchi, T., Hayashi, T., Kubo, Y., Tomiyama, N., Ochi, A. and Hayashi, H. (2021) Association between Family Caregivers and Depressive Symptoms among Community-dwelling Older Adults in Japan: A Cross-Sectional Study during the COVID-19 Pandemic. Archives of Gerontology and Geriatrics, 96, Article ID: 104468. https://doi.org/10.1016/j.archger.2021.104468

[23] Sit, S.M.M., Lam, T.H., Lai, A.Y.K., Wong, B.Y.M., Wang, M.P. and Ho, S.Y. (2021) Fear of COVID-19 and Its Associations with Perceived Personal and Family Benefits and Harms in Hong Kong. Translational Behavioral Medicine, 11, 793-801. https://doi.org/10.1093/tbm/ibab018

[24] Tierolf, B., Geurts, E. and Steketee, M. (2021) Domestic Violence in Families in the Netherlands during the Coronavirus Crisis: A Mixed Method Study. Child Abuse and Neglect, 116, Article ID: 104800. https://doi.org/10.1016/j.chiabu.2020.104800

[25] Wong, B.Y.M., Lam, T.H., Lai, A.Y.K., Wang, M.P. and Ho, S.Y. (2021) Perceived Benefits and Harms of the Covid-19 Pandemic on Family Well-Being and Their Sociodemographic Disparities in Hong Kong: A Cross-Sectional Study. International Journal of Environmental Research and Public Health, 18, Article No. 1217. https://doi.org/10.3390/ijerph18031217

[26] Wong, J.Y.H., Wai, A.K.C., Zhao, S., Yip, F., Lee, J.J., Wong, C.K.H., et al. (2020) Association of Individual Health Literacy with Preventive Behaviours and Family Well-Being during COVID-19 Pandemic: Mediating Role of Family Information Sharing. International Journal of Environmental Research and Public Health, 17, Article No. 8838. https://doi.org/10.3390/ijerph17238838

[27] Xie, M., Wang, X., Zhang, J. and Wang, Y. (2021) Alteration in the Psychologic Status and Family Environment of Pregnant Women Before and During the COVID- 
19 Pandemic. International Journal of Gynecology and Obstetrics, 153, 71-75. https://doi.org/10.1002/ijgo.13575

[28] Beck, K., Vincent, A., Becker, C., Keller, A., Cam, H., Schaefert, R., et al. (2021) Prevalence and Factors Associated with Psychological Burden in COVID-19 Patients and Their Relatives: A Prospective Observational Cohort Study. PLoS ONE, 16, Article ID: e0250590. https://doi.org/10.1371/journal.pone.0250590

[29] Mohammadi, F., Oshvandi, K., Shamsaei, F., Cheraghi, F., Khodaveisi, M. and Bijani, M. (2021) The Mental Health Crises of the Families of COVID-19 Victims: A Qualitative Study. BMC Family Practice, 22, Article No. 94. https://doi.org/10.1186/s12875-021-01442-8

[30] Rahimi, T., Dastyar, N. and Rafati, F. (2021) Experiences of Family Caregivers of Patients with COVID-19. BMC Family Practice, 22, Article No. 137. https://doi.org/10.1186/s12875-021-01489-7

[31] Shah, R., Ali, F.M., Nixon, S.J., Ingram, J.R., Salek, S.M. and Finlay, A.Y. (2021) Measuring the Impact of COVID-19 on the Quality of Life of the Survivors, Partners and Family Members: A Cross-Sectional International Online Survey. BMJ Open, 11, Article ID: e047680. https://doi.org/10.1136/bmjopen-2020-047680

[32] Alhuzimi, T. (2021) Stress and Emotional Wellbeing of Parents due to Change in Routine for Children with Autism Spectrum Disorder (ASD) at Home during COVID-19 Pandemic in Saudi Arabia. Research in Developmental Disabilities, 108, Article ID: 103822. https://doi.org/10.1016/j.ridd.2020.103822

[33] Beach, S.R., Schulz, R., Donovan, H. and Rosland, A.M. (2021) Family Caregiving during the COVID-19 Pandemic. Gerontologist, 61, 650-660.

https://doi.org/10.1093/geront/gnab049

[34] Manning, J., Billian, J., Matson, J., Allen, C. and Soares, N. (2020) Perceptions of Families of Individuals with Autism Spectrum Disorder during the COVID-19 Crisis. Journal of Autism and Developmental Disorders, 51, 2920-2928. https://doi.org/10.1007/s10803-020-04760-5

[35] Tsibidaki, A. (2021) Anxiety, Meaning in Life, Self-efficacy and Resilience in Families with One or More Members with Special Educational Needs and Disability during COVID-19 Pandemic in Greece. Research in Developmental Disabilities, 109, Article ID: 103830. https://doi.org/10.1016/j.ridd.2020.103830

[36] Alessi, J., de Oliveira, G.B., Feiden, G., Schaan, B.D. and Telo, G.H. (2021) Caring for Caregivers: The Impact of the COVID-19 Pandemic on Those Responsible for Children and Adolescents with Type 1 Diabetes. Scientific Reports, 11, Article No. 6812. https://doi.org/10.1038/s41598-021-85874-3

[37] Ehrler, M., Werninger, I., Schnider, B., Eichelberger, D.A., Naef, N., Disselhoff, V., et al. (2021) Impact of the COVID-19 Pandemic on Children with and Without Risk for Neurodevelopmental Impairments. Acta Paediatrica, 110, 1281-1288. https://doi.org/10.1111/apa.15775

[38] Zhao, R., Zhou, Q., Wang, X.W., Liu, C.H., Wang, M., Yang, Q., et al. (2020) Covid-19 Outbreak and Management Approach for Families with Children on Longterm Kidney Replacement Therapy. Clinical Journal of the American Society of Nephrology, 15, 1259-1266. https://doi.org/10.2215/CJN.03630320

[39] Feng, Z., Xu, L., Cheng, P., Zhang, L., Li, L.J. and Li, W.H. (2020) The Psychological Impact of COVID-19 on the Families of First-Line Rescuers. Indian Journal of Psychiatry, 62, S438-S444.

https://doi.org/10.4103/psychiatry.IndianJPsychiatry $1057 \quad 20$

[40] Ying, Y., Ruan, L., Kong, F., Zhu, B., Ji, Y. and Lou, Z. (2020) Mental Health Status 
among Family Members of Health Care Workers in Ningbo, China, during the Coronavirus Disease 2019 (COVID-19) Outbreak: A Cross-Sectional Study. BMC PSychiatry, 20, Article No. 379. https://doi.org/10.1186/s12888-020-02784-w

[41] Day, R.D. (2010) Theories about Family Life. In: Day, R.D., Ed., Introduction to Family Processes, Loutledge, London, 35-56.

[42] Breen, L.J., Lee, S.A. and Neimeyer, R.A. (2021) Psychological Risk Factors of Functional Impairment After COVID-19 Deaths. Journal of Pain and Symptom Management, 61, e1-e4. https://doi.org/10.1016/j.jpainsymman.2021.01.006 